\title{
Cardiovascular Disease Risk and Barriers to Physical Activity
}

\author{
Lisa Aditama ${ }^{1, *}$, Dewi Rahmawati ${ }^{2}$, Nani Parfati ${ }^{1}$, Astrid Pratidina ${ }^{1}$ \\ ${ }^{1}$ Faculty of Pharmacy, University of Surabaya, Jl. Raya Kalirungkut, Surabaya, Indonesia \\ ${ }^{2}$ Postgraduate Program in Pharmaceutical Science, University of Surabaya, Jl. Raya Kalirungkut, Surabaya, Indonesia \\ *Corresponding author. E-mail: lisa_aditama@yahoo.com
}

\section{Abstract}

$\mathrm{B}$ ACKGROUND: The prevalence of obesity is increasing and tends to be higher in adult population groups who are also more educated and employed as a civil/military/police/officers. This study aims to analyze cardiovascular disease (CVD) risk, perceptions about physical activity and barriers experienced to perform physical activity, also stage of change to physical activity.

METHODS: The study design was an observational study, use qualitative methods with in-depth interviews and quantitative analysis CVD risk also stage of change to physical activity questionnaire.

RESULTS: Framingham 10-years CVD risk of obese men in University of Surabaya was $11.97 \%$ (1.70 to 29.90 ) based on lipid profile, and $13.90 \%$ (2.30 to 30.00 ) based on body mass index. Perception of obese men in University of Surabaya regarding physical activity had findings several barriers that can be grouped into time constraint, facility constraint, low motivation, and knowledge about physical activities.

CONCLUSION: In this study we found that 10 -years CVD risk of obese men in University of Surabaya can be categorized as medium risk. There are several barriers regarding life style modification for physical activity and exercise, whereas the subjects included in this study are quite ready to start the program, but improvement for the readiness before starting the program will still be needed.

KEYWORDS: CVD risk, obese men, physical activity

Indones Biomed J. 2015; 7(1): 43-8

\section{Introduction}

Obesity is a complex multifactorial chronic disease that develops from the interaction of genotype and environment. Obesity is essentially occurs from an imbalance between sedentary lifestyle with a high dietary intake of calories.(1)

The prevalence of obesity is higher in the group of the adult population more educated, and employees as a civil/military/police/officers.(2) Men have a greater risk of cardiovascular disease (CVD) than premenopausal women, but a woman's risk factors will increase five to ten years postmenopause, thus becoming the same risk factors as men.(3)

Combating obesity is not only done with the cessation of food intake. Obesity prevention can be done either by lifestyle modification. $(4,5)$ Physical activity or exercise has a great impact on reducing the risk of CVD. Interventions to modify lifestyle needs based on the theory or model that explains the people behavior, and can help to change the behavior by considering and identifying factors that affect the behavior.(6)

Obese people often have rarely healthy behaviors such as physical activity, especially sports, because there are several barriers. $(7,8)$ In order to profile among the 
subjects/ participants in terms of readiness to change their exercise behaviour, it also necessary to interview about the barriers experienced by subjects to perform physical activities, especially regular exercise. Stage of changes to physical activity measurements is a step before starting an educational program.(9)

In men, an increase in physical activity every day lowers abdominal obesity and insulin resistance. In addition, there is a decrease in blood pressure and serum triglycerides, increase high-density lipoprotein (HDL) cholesterol, as well as the improvement of cardiovascular risk.(10-12)

Framingham risk score is a tool that can be used to predict the incidence of CVD within 10 years. These variables included age, body mass index, systolic blood pressure, antihypertensive medication use, current smoking, diabetes and lipid profile. A research by D'Agostino, et al. in 2008, concluded that these tools can be used to measure the risk of CVD in general, easily used by excel spreadsheet required Adult Treatment Panel III Cholesterol Guidelines and validated equations. The same modeling principles and model assessment techniques were applied to these simplified models to predict CVD risk using non laboratory predictors routinely ascertained in primary care based on body mass index (BMI) and lipid profile.(10-12)

\section{Methods}

The design of this study is an observational study, with quantitative analysis of cardiovascular risk factors using CVD risk calculator prepared by D'Agostino and Pencina based on a publication in Circulation 2008. Framingham
Risk Score has a risk classification by look at the resulting score, $<10 \%$ are categorized as low risk, $10-20 \%$ as medium risk and $>20 \%$ as high risk $(10,11)$ and perform perceptions of physical activity with qualitative methods with semistructured interviews, also stage of change to physical activity, using the validated questionnaire The Stages of Change Continuous Measure (URICA-E2).(9) In this study, physical activity means regular exercise e.g. brisk walking, aerobics, jogging, bicycling, swimming, rolling, etc. Such activity should be performed to 3-5 times per week for 2060 minutes per session.

The population in this study are male employees of University of Surabaya who are obese, having already obtained the data that there is an increasing number of employees who are obese and with CVD and did not receive any routine drug treatment. The study took place in University of Surabaya, in February-June 2013.

\section{Results}

Demographics and CVD risk factors in participants are reported in Table 1. Semi-structural interviews were conducted at the University of Surabaya campus Tenggilis and Ngagel, or in the workplace of each participant, with duration varies between 15-20 minutes using recording tool. Calculation of the 10-year risk of vascular disease were done using Framingham Scoring according to BMI and Lipid Profile (Table 2). Obesity-related lifestyle barriers to a regular exercise can be grouped into: time constraint, facility constraint, low motivation, and knowledge barrier.

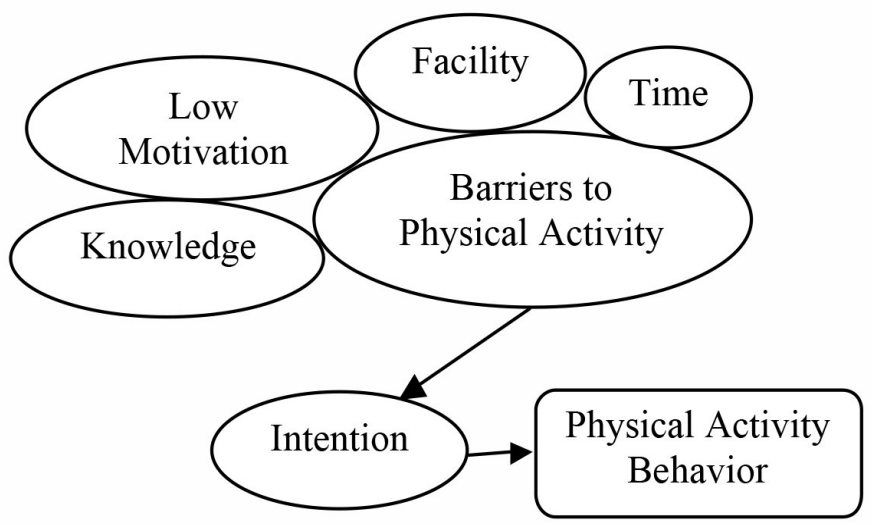

Figure 1. Barriers to Do Exercise. 
Table 1. Demographics and Characteristics of Obese Men.

\begin{tabular}{|cc|}
\hline \multicolumn{1}{|c}{ Demographics } & $\begin{array}{c}\text { Obese Men } \\
(\mathbf{n}=\mathbf{2 3})\end{array}$ \\
\hline Age $($ mean $\pm \mathrm{SD})$ & $44.56 \pm 6.49$ \\
\hline $\mathrm{BMI}($ mean $\pm \mathrm{SD})$ & $31.97 \pm 2.59$ \\
\hline
\end{tabular}

Smoking social history

$\begin{array}{lc}\text { a. Non smoking } & 18(78.26 \%) \\ \text { b. Smoking } & 5(21.74 \%)\end{array}$

Social history of drinking coffee
a. Not drinking coffee
$9(39.13 \%)$
b. $\leq 1 \mathrm{cup} /$ day
$1(4.35 \%)$
c. 1-3 cup/day
$12(53.17 \%)$
d. $\geq 4$ cup/day
$1(4.35 \%)$

Social history of physical activity
a. Not exercising
$8(34.78 \%)$
b. $\leq 1 \mathrm{x} /$ week
$4(17.39 \%)$
c. $1-3 \mathrm{x} /$ week
$3(13.04 \%)$
d. $\geq 4 \mathrm{x} /$ week
$8(34.78 \%)$

Family history of disease
a. Heart disease
$5(21.74 \%)$
b. Diabetes Mellitus
$3(13.04 \%)$
c. Hypertension
$5(21.74 \%)$
d. Dyslipidemia
$3(21.72 \%)$
e. Kidney disease
$1(4.35 \%)$
f. Hyperuricemia
$1(4.35 \%)$
g. Osteoarthritis
$1(4.35 \%)$

Level of education
a. Low education
$7(30.43 \%)$
b. High education
$16(69.56 \%)$

Drugs consumed in last 3 months
a. Lipid lowering agent
$1(4.35 \%)$
b. Anti-Hypertension
$3(13.04 \%)$
c. Corticosteroids
$0(0 \%)$
d. Others
$3(13.04 \%)$

Table 2. Framingham 10-year CVD Risk According to BMI and Lipid Profile.

\begin{tabular}{|c|c|c|}
\hline Name & $\begin{array}{c}\text { Framingham } 10 \text {-year } \\
\text { CVD risk based on } \\
\text { BMI }\end{array}$ & $\begin{array}{c}\text { Framingham 10-year } \\
\text { CVD risk based on } \\
\text { Lipid Profile }\end{array}$ \\
\hline SB1 & $10.40 \%$ & $8.10 \%$ \\
\hline SB2 & $6.00 \%$ & $5.70 \%$ \\
\hline SB3 & $6.10 \%$ & $6.80 \%$ \\
\hline SB4 & $14.00 \%$ & $13.30 \%$ \\
\hline SB5 & $21.10 \%$ & $24.30 \%$ \\
\hline SB6 & $6.20 \%$ & $5.10 \%$ \\
\hline SB7 & $7.00 \%$ & $6.20 \%$ \\
\hline SB8 & $16.60 \%$ & $11.30 \%$ \\
\hline SB9 & $12.10 \%$ & $9.50 \%$ \\
\hline SB10 & $12.60 \%$ & $9.10 \%$ \\
\hline SB11 & $11.60 \%$ & $9.10 \%$ \\
\hline SB12 & $10.00 \%$ & $10.80 \%$ \\
\hline SB13 & $16.10 \%$ & $13.20 \%$ \\
\hline SB14 & $13.30 \%$ & $16.00 \%$ \\
\hline SB15 & $14.20 \%$ & $6.90 \%$ \\
\hline SB16 & $30.00 \%$ & $23.60 \%$ \\
\hline SB17 & $22.20 \%$ & $12.80 \%$ \\
\hline SB18 & $30.00 \%$ & $29.90 \%$ \\
\hline SB19 & $10.00 \%$ & $10.60 \%$ \\
\hline SB20 & $30.00 \%$ & $22.00 \%$ \\
\hline SB21 & $6.70 \%$ & $1.70 \%$ \\
\hline SB22 & $2.30 \%$ & $6.60 \%$ \\
\hline SB23 & $11.30 \%$ & $12.60 \%$ \\
\hline \multirow{3}{*}{$\begin{array}{l}\text { 10-year } \\
\text { CVD } \\
\text { risk }\end{array}$} & Mean $=13.90 \%$ & Mean $=11.97 \%$ \\
\hline & $\operatorname{Min}=2.30 \%$ & $\operatorname{Min}=1.70 \%$ \\
\hline & Max $=30.00 \%$ & $\operatorname{Max}=29.90 \%$ \\
\hline
\end{tabular}




\section{Time Constraint}

Other activities beside routine or working hours are time-consuming, so exercise become obstacles for the participants. Moreover due to fatigue from working, time is often used for resting than for doing regular exercise. Participant 2: "Since I go to the office early in the morning, the exercise should be in the afternoon, probably started from 17:00. However, usually I leave office at 15:00 and arrive at home near 16:30. In addition, since my wife also works, I have to help her to do some domestic tasks. The tasks are so tiresome and require plenty of time, when the tasks are done, it's already near the bed time. Then in the morning, I have to wake up at 5:00, so it's quite impossible to do any exercise." wanted to go along when I plan to have an exercise, then my exercise will be canceled." Participant 2: "If the children go along with me, they tend to tease or play, so my exercise will be disturbed and eventually canceled." Participant 3: "I often feel lazy and don't like to perspire. I have been lazy since I was young."

Another obstacle for doing exercise is when friends or guests come. Participant 6: "I was planning to exercise, but then guest came unexpectedly. So I had to cancel the exercise."

\section{Knowledge Barrier}

Another obstacle for doing exercise is limited knowledge

Table 3. Stage of Change to Physical Activity in Obese Men.

\begin{tabular}{lc}
\hline \multicolumn{1}{c}{ Stage of Change } & Subjects \\
\hline Pre-contemplation non believers in physical activity & 0 \\
PBPre-contemplation believers in physical activity & 3 \\
Contemplation & 18 \\
Preparation & 2 \\
Action & 0 \\
Maintenance & 0 \\
\hline & Total \\
\hline
\end{tabular}

\section{Facility Constraint}

Facility constraint was a great limitation for participants to exercise regularly. Participant 4: "The desire to exercise was there, but sometimes there are not enough tools, for example bicycle. Therefore the exercise can't be done." Constraint of place to exercise can be a barrier for doing regular exercise. A participant argued that in order to exercise they must have/rent a place to exercise. Participant 2: "Usually we rent a place somewhere to exercise, but if the place was already rented, then our exercise is canceled."

\section{Low Motivation}

Interview results with participants indicate there are many obstacles because of the low motivation, including lack of encouragement and laziness. Participant 1:"If my children on how to exercise and what kind of exercise. For example, lack of knowledge on types of exercise that can be done with or without tools, also time and category of sports that can be done in accordance with their conditions. A participant said that there is no gym equipment then he can not do sports. Participant 4: "Sport equipments are necessary for doing exercises. Since my bicycle is already broken, and I haven't bought a new one, I don't exercise regularly now."

Another finding for barrier to do exercise is to do exercise regularly. The regular exercise requires additional time. Participant 5: "My spare time is so limited, whereas exercise takes at least approximately 1 hour or so. When I have such free time, I'd better sleep." 


\section{Discussion}

Based on Framingham Risk Score, we found 11.97\% (1.70 to $29.90 \%$ ) of CVD risk in 10 years based on lipid profile and $13.90 \%$ (2.30 to $30.00 \%$ ) of CVD risk in 10 years based on BMI from obese men in University of Surabaya, that overall can be categorized as medium risk. CVD risk can be reduced with weight loss and lipid control by increasing HDL through a healthy lifestyle. According to Abdul Manaf study, healthcare team work (dietitians, nutritionist, physicians, physiotherapist, psychologist, and exercise instructor) is needed to establish body weight reducing programme in workplace. Through the intervention, there is significant reduction of body weight $(-2.9 \mathrm{~kg}, p<0.001)$, BMI $(-1.2 \mathrm{~kg} / \mathrm{m} 2, p<0.001)$, body fat percentage $(-2.4 \%$, $p<0.05)$, waist circumference $(-7.5 \mathrm{~cm}, p<0.001)$, serum fasting glucose $(-0.2 \mathrm{mmol} / \mathrm{L}, p<0.01), \mathrm{HbAlc}(-0.1 \%$, $p<0.02)$, and triglyceride $(-0.2 \mathrm{mmol} / \mathrm{L}, p<0.001) .(13)$

There are several barriers to regular exercise that we obtained from the participants regarding lifestyle modification that focused on physical activity and exercise, and can be grouped into time constraint, facility constraint, low motivation, and knowledge about exercise. Lifestyle modification education is one of suitable therapies for obesity patients.(10)

Stage of changes in physical activity indicated that the average subjects included in the category are quite ready to start the program (contemplation and pre-contemplation) but still need to improve the readiness before starting the program.

\section{Conclusion}

In this study we found that 10 -years CVD risk of obese men in University of Surabaya overall can be categorized as medium risk. There are several barriers regarding life style modification for physical activity and exercise, whereas the average subjects included in the category are quite ready to start the program, but improvement for the readiness before starting the program will still be needed.

Based on this study, as an educational institution, University of Surabaya is recommended to:

1. Improve the existed sports facilities, so that employees and faculty member would be interested in doing regular sports activities.
2. Make an executive club for employees who are obese to exercise together.

\section{Acknowledgement}

We thanks to the Indonesia Higher Education Board (DIKTI) which has provided research grants in a competitive grant scheme.

\section{References}

1. World Health Organization [homepage on the Internet]. Media centre: Obesity and overweight; 2012 [update 2011; cited 2012 March 9]. Available from: http://www.who.int/mediacentre/factsheets/fs $311 /$ en/.

2. Badan Penelitian dan Pengembangan Kesehatan Kementrian Kesehatan RI. Laporan Hasil Riset Kesehatan Dasar Indonesia (Riskesdas) 2010. Jakarta: Departemen Kesehatan Republik Indonesia; 2010.

3. Rossouw JE. Hormones, genetic factors, and gender differences in cardiovascular disease. Cardiovasc Res. 2002; 53: 550-7.

4. Santo AC, Ebrahim S, Barros H. Gender, socio-economic status and metabolic syndrome in middle-age and old adults. BMC Public Health. 2008; 8: 62. doi: 10.1186/1471-2458-8-62.

5. Sodjinou R, Agueh V, Fayoni B, Delisle H. Obesity and cardiometabolic risk factor in urban adult of Benin: relationship with socio-economic status, urbanisation, and lifestyle patterns. BMC Public Health. 2008; 8: 84. doi: 10.1186/1471-2458-8-84.

6. Shumaker SA, Ockene JK, Riekert KA, editors. The Handbook of Health Behavior Change. 3rd ed. New York: Springer Publishing Company, LLC; 2009.

7. McMurray RG, Ainsworth BE, Harrell JS, Griggs TR, Williams OD Is physical activity or aerobic power more influential on reducing cardiovascular disease risk factors? Med Sci Sports Exerc. 1998; 30: $1521-9$.

8. D'Agostino RB Sr, Vasan RS, Pencina MJ, Wolf PA, Cobain M, Massaro JM, et al. General Cardiovascular Risk Profile for Use in Primary Care : The Framingham Heart Study. Circulation. 2008; 117: 743-53.

9. Lerdal A, Moe B, Digre E, Harding T, Kristensen F, Grov EK, et al. Stage of Change -- Continuous Measure (URICA-E2): Psychometric of a Norwegian Version. J Adv Nurs. 2009; 65 : 193-202.

10. Expert Panel on Detection, Evaluation, and Treatment of High Blood Cholesterol in Adults. Executive Summary of the third report of The National Cholesterol Education Program (NCEP) Expert panel on detection, evaluation, and treatment of high blood cholesterol in adults (Adult treatment panel III). JAMA. 2001; 285: 2486-97.

11. Expert Panel on Detection, Evaluation, and Treatment of High Blood Cholesterol in Adults. Third Report of the National Cholesterol Education Program (NCEP) Expert Panel on Detection, Evaluation, and Treatment of High Blood Cholesterol in Adults (Adult Treatment Panel III) Final Report. Circulation. 2002; 106: 3143421. 
12. Jette M, Sidney K, Blumchen G. Metabolic equivalents (METS) in exercise testing, exercise prescription, and evaluation of functional capacity. Clin Cardiol. 1990; 13: 555-65.
13. Abdul Manaf Z, Shahar S, Ramli A, Ibrahim N, Rajikan R, Abdul Aziz N, et al. The Effectiveness of a structured weight reduction programme at workplace using a multidisciplinary approach. Obesity reviews 2014 (Suppl. 2): 98-128. 